\title{
Evaluation of Risk Factors for Preterm Birth Outcome in Gujarat, India
}

\author{
Pratibha Rathod ${ }^{1}$, Ajesh Desai $^{2}$, Divya Chandel ${ }^{3}$ \\ ${ }^{1}$ Department of Zoology, BMT and HG, Gujarat University, Ahmedabad, India. \\ ${ }^{2}$ Obstetrics and Gynaecology Department, B J Medical College, Ahmedabad, India. \\ ${ }^{3}$ Department of Zoology, Biomedical Technology and Human Genetics, Gujarat University, Ahmedabad, India. \\ Corresponding Author: Divya Chandel
}

DOI: https://doi.org/10.52403/ijhsr.20220123

\begin{abstract}
Background: Preterm birth (PTB) is a leading cause of neonatal survival complications, mortality, and morbidity worldwide. In India $35 \%$ of all neonatal deaths are due to PTB with $36^{\text {th }}$ global ranking, hence, India's healthcare sector has been working towards reducing the rate of PTB effectively.

Objective: This study aimed to assess the risk factors such as environmental and pathophysiological causes associated with preterm birth in the population of Gujarat, India.

Materials and Methods: In this study, multivariate random sampling was performed and systematically 200 pregnant mothers [PTB $<37$ weeks $(\mathrm{N}=100)$, Full-term $>37$ weeks $(\mathrm{N}=100)]$ were chosen after excluding mothers with vaginal infection, multiple gestations, fetal anomalies, noncephalic presentation, cesarean delivery, and pregnancy with Mullerian anomalies. Statistical analysis was performed by Chi-square test, and variables with p-value $<0.05$ were considered statistically significant.

Results: Out of all the variables, maternal age below 20 years, extreme BMI, high blood pressure during pregnancy, maternal health complications, medication and doctor's consultation were highly significant $(\mathrm{p}<0.0001)$. Furthermore, variables like type of area, diet, education, Hb levels below 9 $\mathrm{g} / \mathrm{dL}$ and above $13 \mathrm{~g} / \mathrm{dL}$ and blood-group of the mother were also significantly associated with PTB outcome ( $\mathrm{p}<0.05)$. Among the sub-categories of PTB (extreme-, very-, moderate/late- PTB), maternal age, $\mathrm{Hb}$ level and the past obstetric outcome showed very high significance $(\mathrm{p}<0.0001)$.

Conclusion: For the prediction of birth outcome, mother's internal physiological and lifestyle factors need to be taken into consideration, and mothers at risk priorly can be screen out, followed by proper healthcare assistance to decrease the preterm birth rate and its consequences.
\end{abstract}

Key Words: Preterm birth, maternal age, blood pressure, past obstetric outcome, risk factors

\section{INTRODUCTION}

The World Health Organisation (WHO) defines "Preterm" as the live birth of infants before completing 37 weeks of pregnancy. Preterm birth (PTB) can be categorised into extreme preterm birth $(<28$ weeks), very preterm birth (28-32 weeks) and moderate/late preterm birth (32-37 weeks). ${ }^{[1]}$ Premature newborns, especially those who are born before 32 weeks of gestation, are extremely vulnerable and need neonatal intensive care services for survival.
Such facilities and availability are not well established in the middle- and low-income countries making neonatal survival more challenging. [1] Among the contributing complications in neonatal death, preterm delivery remains the leading cause, along with intrapartum-related complications and sepsis or meningitis. ${ }^{2]}$ According to 2020 estimates of the UN, each year India accounts for 522,000 neonates of the global neonatal deaths. ${ }^{[3]}$ Moreover, analysing the top five causes of neonatal mortality, it 
becomes evident that the proportion of neonatal death has increased from $41 \%$ in 1990 to $56 \%$ in 2012, reflecting the relative lack in newborn survival growth in India. Furthermore, the risk of mortality is inversely proportional to the gestational age, and the highest risk is seen in those born very early $(<28$ weeks), as nearly $95 \%$ of these babies die without specialised newborn care. ${ }^{[4]}$ There are many reasons for the early birth outcome and other pregnancy-related complications, including teenage or above 35 years of maternal age, extremely low or high BMI of the mother, low $\mathrm{Hb}$ levels (anaemia), previous obstetric complications, cervical insufficiency, infection or inflammation and maternal physical or mental stress. ${ }^{[5-12]}$

Despite recent medical advances, the rate of preterm birth instances is increasing worldwide. It is a multifactorial condition, and the puzzling heterogeneity of the risk factors for premature delivery have not yet been confirmed. Interpreting the associative etiological factors will help identify highrisk pregnancies and reduce the mother and baby's mortality and morbidity due to complicated early parturition. Hence, this study was carried out to identify risk factors for preterm birth so that early interventions can be given for healthy full-term outcomes.

\section{MATERIALS AND METHODS Study design:}

This population-based prospective cohort study was carried out at the GMERS (Gujarat Medical Education and Research Society) hospital of Ahmedabad and included the population of Gujarat, India. The study was approved by the Institutional ethical committee of Gujarat University (GUJIEC_03_2017) and GMERS ethical committee (GMERSMCS/IEC/37/2018). The pregnant women were explained the purpose of this study and informed consent were taken. The medical examination was performed by the doctor, and specific points were noted in a detailed proforma with pedigree analysis. In total, 200 mothers (Control mothers-100, Preterm Birth mothers-100) were selected. All pregnant women were enrolled in the study after screening through inclusion criteria like confirming gestation age $<37$ weeks (Cases), >37 weeks (Control) by LMP or sonography, cephalic presentation and normal delivery. Mothers with vaginal infection, multiple gestations, pregnancy with Mullerian anomalies, cesarean delivery and non-cephalic presentation were excluded. Inclusion and exclusion criteria were decided to make sampling more uniform for both the groups and eliminate conditions which primarily known to be linked with PTB or related complications. All data were recorded in the individual files and were computerised using a standardised data entry application.

The following demographic factors were considered as possible variables: mother's age, area of living, diet, addiction of tobacco, type of family, work during pregnancy, occupation, family income, education, body mass index (BMI), blood group, haemoglobin level, menstrual pain before conception, history of prior obstetric outcomes and maternal illness during pregnancy, blood pressure, doctor's consultation and medication, gravida/parity, interpregnancy interval, as well as neonate's gender, birth weight, delivery time and persisting complication if any were noted.

"Gestational age at birth" was defined as the completed weeks of gestation starting from the date of the last menstrual period to the date of delivery as mentioned in each woman's clinical record. "Preterm birth" was defined as the birth before 37 weeks of gestation. "Maternal age" was defined as the mother's age at the time of giving birth (18 to 38 years). "Type of area" referred to the locality in which the individual resided and was divided into three categories: rural, urban and slum. "Type of diet" was classified into two categories: Vegetarian diet and mixed diet, which includes vegetarian as well as nonvegetarian food. "Addiction" of consuming tobacco (chewing/smoking) by both mother and father was noted. "Family 
structure" referred to the family settlement of the individual: Nuclear family (about 4-5 members in a family) and Joint family (more than five members in a family). "Work during pregnancy and occupation" was categorised by the kind of work women were engaged with during the pregnancy. "Family income" referred to the total earning of a family every month to reveal the economic condition. "Education" referred to the mother's literacy and is divided into two major groups: literate and illiterate. The literate ones were further divided into categories like primary, middle, high and graduate. "The body mass index (BMI)" is the value derived from the mass and height of the individual, which was documented in each woman's clinical record. "Blood group": The individuals belonging to all blood groups were taken into consideration $\mathrm{A}, \mathrm{B}, \mathrm{AB}$ and $\mathrm{O}$. "Hb": Haemoglobin status was determined by haemoglobin level or hematocrit at the last trimester. "Menstrual pain": Females were divided on the basis of having cramps during periods before pregnancy. "Previous obstetric complication": Women with a previous medical history of stillbirth/ miscarriage/spontaneous abortion (SA) and prior PTB or any other illness during pregnancy were noted down. "Blood pressure" (BP) was divided into three categories: Hypotension/low BP, normal $\mathrm{BP}$, hypertension/high BP. "Doctor's consultation and medication": mothers' frequency of visiting doctor during pregnancy along with the regularity in the medication intake were noted from the records. "Gravida/Parity" referred to the number of times females conceived. "Interpregnancy interval" was taken into consideration by noting down the gap between deliveries. "Birth weight of neonate", "Sex of neonate", and "Fetal complications" were also recorded and analysed.

\section{Statistical analysis}

The comparison between controls and cases for all the potential risk factors are represented by percentages and counts. Statistical analysis was performed using GraphPad Prizm 7 software. All odds and adjusted odds ratios were reported with 95 $\%$ confidence intervals (CIs). A Chi-square test was performed, and the p-values for all hypothesis tests were two-sided. Statistical significance was considered at $\mathrm{p}<0.05$.

\section{RESULTS}

A total of 200 pregnant mothers are included in this study, and the detailed results of the analysis are presented in Table 1. Maternal age below 20 and above 25 years showed significantly higher PTB chances $(\mathrm{p}<0.0001)$. Moreover, we observed that a higher number of PTBs fall below 20 years of age rather than above 35 years of age. When PTBs were further divided into sub-categories (Extreme PTB $<28$ weeks; Very PTB 28-32 weeks and Moderate PTB 32-37 weeks), it was found to be statistically significant at $p<0.0001$ (Table 2). In the case of area, significantly higher $(p<0.001)$ frequency of preterm births were observed in rural and slum setting.

Based on the type of diet, it was noted that 110 mothers were vegetarian, while 90 were having a mixed diet (both vegetarian and nonvegetarian). More normal deliveries were observed in vegetarian diet eating mothers, while more PTBs occurred in a mixed diet $(p<0.05)$. In the case of addiction, the number of tobacco addicted fathers and mothers were non-significantly higher in the PTB group. A comparatively higher number of normal births were recorded in a joint family than the nuclear one $(p>0.05)$. In our study population, most of the families were economically backward, and a high number of mothers were engaged in household work. Family structure, family's income and mother's occupation were found to be statistically nonsignificant. Education had an impact on PTB, and the illiterate group showed a significant $(p<0.05)$ risk of PTB than the literate ones. BMI (Body Mass Index) showed a considerable influence on the 
chances of having PTB; where compared to the control mothers, preterm mothers were significantly $(p>0.0001)$ higher in number, in the categories of severely underweight, underweight, overweight and obese. While observing within the PTB sub-categories, the BMI values were nonsignificant (Table 2 ). In blood groups, the number of PTBs were found significantly higher $(p<0.05)$ in the mothers with blood group $B$, followed by the $\mathrm{AB}$ group, while the $\mathrm{O}$ and $\mathrm{A}$ blood group showed fewer PTBs than the control group. The haemoglobin levels of mothers showed a significant impact on PTB outcomes. The $\mathrm{Hb}$ range between $7-9 \mathrm{~g} / \mathrm{dL}$ and above $13 \mathrm{~g} / \mathrm{dL}$ significantly $(\mathrm{p}<0.05)$ increased PTB chances, while the chances of PTB were lowered in the range of 9-13 $\mathrm{g} / \mathrm{dL}$. Further analysing sub-categories of PTB, very high significance was observed for low $\mathrm{Hb}(7-9 \mathrm{~g} / \mathrm{dL})$ in the extreme PTB group (p<0.0001) (Table 2). Out of a total of 200 mothers, 97 females had a history of painful periods (menstrual cramps), but no statistical correlation was observed between the two groups. Previous obstetric complications (stillbirth/PTB, Miscarriage/ Spontaneous Abortion) showed an impact on the consecutive pregnancies. The frequency of repeated PTBs and a history of miscarriage and spontaneous abortion were observed higher in cases compared to the controls though data was statistically nonsignificant. However, in the statistical analysis within PTB sub-categories, the data proved to be highly significant for extreme and very PTB. Maximum miscarriages and spontaneous abortions fall in these groups compared to moderate PTB ( $\mathrm{p}<0.0001)$ (Table 2). The overall maternal healthrelated complications during pregnancy such as abdominal pain, fever, jaundice, vertigo, severe vomiting, unusual swelling, drying of amniotic fluid, typhoid, bleeding during pregnancy, cervical incompetence showed a highly significant $(\mathrm{p}<0.001)$ impact on preterm birth outcome. We observed the highest full-term births (control) in the group of mothers with a normal BP range, while significantly higher PTBs were observed in the high BP group ( $\mathrm{p}<0.0001)$. Furthermore, looking within the sub-categories of PTB, the BP criterion was found to be nonsignificant (Table 2). The doctor's consultation also influenced the pregnancy outcome, and significantly $(\mathrm{p}<$ 0.0001) higher PTBs were observed when doctor consultation was irregular. Likewise, in terms of medication, the chances of normal births were higher in the group of individuals who maintained regularity in medication uptake. In contrast, irregular medicating mothers showed a significantly increased number of PTBs ( $p<0.0001)$. The data of parity and gap between pregnancies were found statistically nonsignificant.

Table 1. Social, physical and obstetric variables of controls and cases.

\begin{tabular}{|c|c|c|c|c|c|}
\hline CRITERIA & $\begin{array}{l}\text { Total No. } \\
\text { N=200 }(\%)\end{array}$ & $\begin{array}{l}\text { FULL TERM N=100 } \\
(\%)\end{array}$ & $\begin{array}{l}\text { PRETERM BIRTH N=100 } \\
(\%)\end{array}$ & $\begin{array}{l}\text { Chi-square } \\
\text { value }\end{array}$ & $\begin{array}{l}\text { p- } \\
\text { value }\end{array}$ \\
\hline \multicolumn{6}{|c|}{ MATERNAL AGE } \\
\hline Below 20 & $41(20.5 \%)$ & $9(9 \%)$ & $32(32 \%)$ & 35.19 & $* * * *$ \\
\hline $20-25$ & $85(42.5 \%)$ & $62(62 \%)$ & $23(23 \%)$ & & \\
\hline $26-30$ & $50(25 \%)$ & $21(21 \%)$ & $29(29 \%)$ & & \\
\hline $31-35$ & $19(9.5 \%)$ & $07(7 \%)$ & $12(12 \%)$ & & \\
\hline Above 35 & $05(2.5 \%)$ & $01(1 \%)$ & $04(4 \%)$ & & \\
\hline \multicolumn{6}{|c|}{ TYPE OF AREA } \\
\hline Rural & $60(30 \%)$ & $21(21 \%)$ & $39(39 \%)$ & 13.36 & $* *$ \\
\hline Urban & $123(61.5 \%)$ & $74(74 \%)$ & $49(49 \%)$ & & \\
\hline Slum & $17(8.5 \%)$ & $05(5 \%)$ & $12(12 \%)$ & & \\
\hline \multicolumn{6}{|c|}{ TYPE OF DIET } \\
\hline Vegetarian & $110(55 \%)$ & $62(62 \%)$ & $48(48 \%)$ & 3.96 & $*$ \\
\hline Mixed & $90(45 \%)$ & $38(38 \%)$ & $52(52 \%)$ & & \\
\hline \multicolumn{6}{|c|}{ ADDICTION OF MOTHER } \\
\hline Tobacco & $18(9 \%)$ & $05(5 \%)$ & $13(13 \%)$ & 0.377 & NS \\
\hline Smoking & $01(0.5 \%)$ & $00(0 \%)$ & $01(1 \%)$ & & \\
\hline \multicolumn{6}{|c|}{ ADDICTION OF FATHER } \\
\hline Tobacco & $102(51 \%)$ & $49(49 \%)$ & $53(53 \%)$ & 0.27 & NS \\
\hline Smoking & $47(23.5 \%)$ & $18(18 \%)$ & $29(29 \%)$ & & \\
\hline
\end{tabular}


Pratibha Rathod et.al. Evaluation of risk factors for preterm birth outcome in Gujarat, India.

\begin{tabular}{|c|c|c|c|c|c|}
\hline \multicolumn{6}{|c|}{ Table 1 Continued... } \\
\hline \multicolumn{6}{|l|}{ FAMILY STRUCTURE } \\
\hline Joint & $105(52.5 \%)$ & $58(58 \%)$ & $47(47 \%)$ & 2.426 & NS \\
\hline Nuclear & $95(47.5 \%)$ & $42(42 \%)$ & $53(53 \%)$ & & \\
\hline \multicolumn{6}{|l|}{ WORK DURING PREGNANCY } \\
\hline Yes & $129(64.5 \%)$ & $71(71 \%)$ & $58(58 \%)$ & 3.69 & NS \\
\hline No & $71(35.5 \%)$ & $29(29 \%)$ & $42(42 \%)$ & & \\
\hline \multicolumn{6}{|l|}{ OCCUPATION } \\
\hline Housewife & $142(71 \%)$ & $69(69 \%)$ & $73(73 \%)$ & 13.78 & NS \\
\hline House Cleaning & $8(4 \%)$ & $06(6 \%)$ & $02(2 \%)$ & & \\
\hline Farming & $19(9.5 \%)$ & $11(11 \%)$ & $08(8 \%)$ & & \\
\hline Labor work & $13(6.5 \%)$ & $08(8 \%)$ & $05(5 \%)$ & & \\
\hline Tailor & $8(4 \%)$ & $05(5 \%)$ & $03(3 \%)$ & & \\
\hline Teacher & $6(3 \%)$ & $00(0 \%)$ & $06(6 \%)$ & & \\
\hline Factory work & $2(1 \%)$ & $00(0 \%)$ & $02(2 \%)$ & & \\
\hline Rag picker & $1(0.5 \%)$ & $00(0 \%)$ & $01(1 \%)$ & & \\
\hline Idol maker & $1(0.5 \%)$ & $01(1 \%)$ & $00(0 \%)$ & & \\
\hline \multicolumn{6}{|l|}{ FAMILY INCOME } \\
\hline Around 5000 & $19(9.5 \%)$ & $10(10 \%)$ & $09(9 \%)$ & 7.49 & NS \\
\hline $5000-10000$ & $64(32 \%)$ & $27(27 \%)$ & $37(37 \%)$ & & \\
\hline $11000-15000$ & $65(32.5 \%)$ & $31(31 \%)$ & $34(34 \%)$ & & \\
\hline $16000-20000$ & $40(20 \%)$ & $22(22 \%)$ & $18(18 \%)$ & & \\
\hline More than 25000 & $12(6 \%)$ & $10(10 \%)$ & $02(2 \%)$ & & \\
\hline \multicolumn{6}{|l|}{ EDUCATION } \\
\hline Illiterate & $59(29.5 \%)$ & $23(23 \%)$ & $36(36 \%)$ & 10.61 & $*$ \\
\hline Literate & $141(70.5 \%)$ & $77(77 \%)$ & $64(64 \%)$ & & \\
\hline Primary & $63(31.5 \%)$ & $36(36 \%)$ & $27(27 \%)$ & 4.063 & \\
\hline Middle & $44(22 \%)$ & $23(23 \%)$ & $21(21 \%)$ & & \\
\hline High & $20(10 \%)$ & $07(7 \%)$ & $13(13 \%)$ & & \\
\hline Graduate & $14(7 \%)$ & $11(11 \%)$ & $03(3 \%)$ & & \\
\hline \multicolumn{6}{|l|}{ BMI } \\
\hline Severely Underweight & $08(4 \%)$ & $01(1 \%)$ & $07(7 \%)$ & 19.55 & $* * *$ \\
\hline Underweight & $23(11.5 \%)$ & $07(7 \%)$ & $16(16 \%)$ & & \\
\hline Normal & $113(56.5 \%)$ & $71(71 \%)$ & $42(42 \%)$ & & \\
\hline Overweight & $48(24 \%)$ & $19(19 \%)$ & $29(29 \%)$ & & \\
\hline Obese & $08(4 \%)$ & $02(2 \%)$ & $06(6 \%)$ & & \\
\hline \multicolumn{6}{|l|}{ BLOOD GROUP } \\
\hline $\mathrm{A}$ & $35(17.5 \%)$ & $23(23 \%)$ & $12(12 \%)$ & 8.99 & $*$ \\
\hline B & $73(36.5 \%)$ & $28(28 \%)$ & $45(45 \%)$ & & \\
\hline $\mathrm{AB}$ & $19(9.5 \%)$ & $08(8 \%)$ & $11(11 \%)$ & & \\
\hline $\mathrm{O}$ & $73(36.5 \%)$ & $41(41 \%)$ & $32(32 \%)$ & & \\
\hline \multicolumn{6}{|l|}{ HAEMOGLOBIN } \\
\hline 7 to 9 & $37(18.5 \%)$ & $14(14 \%)$ & $23(23 \%)$ & 7.982 & $*$ \\
\hline 9 to 11 & $74(37 \%)$ & $38(38 \%)$ & $36(36 \%)$ & & \\
\hline 11 to 13 & $79(39.5 \%)$ & $46(46 \%)$ & $33(33 \%)$ & & \\
\hline Above 13 & $10(5 \%)$ & $02(2 \%)$ & $08(8 \%)$ & & \\
\hline \multicolumn{6}{|l|}{ MENSTRUAL PAIN } \\
\hline Yes & $97(48.5 \%)$ & $55(55 \%)$ & $42(42 \%)$ & 3.38 & NS \\
\hline No & $103(51.5 \%)$ & $45(45 \%)$ & $58(58 \%)$ & & \\
\hline \multicolumn{6}{|c|}{ PREVIOUS OBSTETRIC COMPLICATION } \\
\hline Spontaneous abortion/Miscarriage & $20(10 \%)$ & $05(5 \%)$ & $15(15 \%)$ & 0.011 & NS \\
\hline Stillbirth/PTB & $38(19 \%)$ & $07(7 \%)$ & $31(31 \%)$ & & \\
\hline MOTHER'S HEALTH COMPLIC & ION DURING & PREGNAN & & & \\
\hline Abdominal pain & $14(7 \%)$ & $06(6 \%)$ & $08(8 \%)$ & 31.27 & $* * *$ \\
\hline Fever & $43(21.5 \%)$ & $14(14 \%)$ & $29(29 \%)$ & & \\
\hline Jaundice & $06(3 \%)$ & $01(1 \%)$ & $05(5 \%)$ & & \\
\hline Vertigo & $03(1.5 \%)$ & $03(3 \%)$ & $00(0 \%)$ & & \\
\hline Severe vomiting & $08(4 \%)$ & $02(2 \%)$ & $06(6 \%)$ & & \\
\hline Unusual swelling & $13(6.5 \%)$ & $09(9 \%)$ & $04(4 \%)$ & & \\
\hline Drying of amniotic fluid & $21(10.5 \%)$ & $00(0 \%)$ & $21(21 \%)$ & & \\
\hline Typhoid & $02(1 \%)$ & $00(0 \%)$ & $02(2 \%)$ & & \\
\hline Bleeding during pregnancy & $04(2 \%)$ & $00(0 \%)$ & $04(4 \%)$ & & \\
\hline Cervical Incompetence & $03(1.5 \%)$ & $00(0 \%)$ & $03(3 \%)$ & & \\
\hline BLOOD PRESSURE & & & & & \\
\hline Low & $57(28.5 \%)$ & $32(32 \%)$ & $25(25 \%)$ & 43.5 & $* * * *$ \\
\hline Normal & $77(38.5 \%)$ & $56(56 \%)$ & $21(21 \%)$ & & \\
\hline High & $66(33 \%)$ & $12(12 \%)$ & $54(54 \%)$ & & \\
\hline DOCTOR'S CONSULTATION & & & & & \\
\hline Regular & $118(59 \%)$ & $76(76 \%)$ & $42(42 \%)$ & 23.89 & $* * * *$ \\
\hline Irregular & $82(41 \%)$ & $24(24 \%)$ & $58(58 \%)$ & & \\
\hline & & 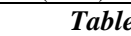 & & & \\
\hline
\end{tabular}




\begin{tabular}{|c|c|c|c|c|c|}
\hline \multicolumn{6}{|l|}{ MEDICATION } \\
\hline Regular & $153(76.5 \%)$ & $91(91 \%)$ & $62(62 \%)$ & 23.39 & ***** \\
\hline Irregular & $47(23.5 \%)$ & $09(9 \%)$ & $38(38 \%)$ & & \\
\hline \multicolumn{6}{|l|}{ GRAVIDA/ PARITY } \\
\hline Primigravida & $93(46.5 \%)$ & $51(51 \%)$ & $42(42 \%)$ & 1.63 & NS \\
\hline Multigravida & $107(53.5 \%)$ & $49(49 \%)$ & $58(58 \%)$ & & \\
\hline \multicolumn{6}{|l|}{ INTERPREGNANCY INTERVAL } \\
\hline Around 1 year & $22(11 \%)$ & $08(8 \%)$ & $14(14 \%)$ & 3.83 & NS \\
\hline 2 years & $42(21 \%)$ & $18(18 \%)$ & $24(24 \%)$ & & \\
\hline $2-3$ years & $22(11 \%)$ & $14(14 \%)$ & $08(8 \%)$ & & \\
\hline More than 3 years & $21(10.5 \%)$ & $09(9 \%)$ & $12(12 \%)$ & & \\
\hline \multicolumn{6}{|l|}{ BIRTH WEIGHT OF NEONATE } \\
\hline Below $1 \mathrm{~kg}$ & $32(16 \%)$ & $00(0 \%)$ & $32(32 \%)$ & 65.57 & $* * * *$ \\
\hline $1-2 \mathrm{~kg}$ & $27(13.5 \%)$ & $04(4 \%)$ & $23(23 \%)$ & & \\
\hline More than $2 \mathrm{~kg}$ & $139(69.5 \%)$ & $96(96 \%)$ & $43(43 \%)$ & & \\
\hline $2-2.5$ & $50(35.97 \%)$ & $23(23 \%)$ & $27(27 \%)$ & & \\
\hline $2.6-3.0$ & $60(43.17 \%)$ & $47(47 \%)$ & $13(13 \%)$ & & \\
\hline More than 3 & $29(20.86 \%)$ & $26(26 \%)$ & $03(3 \%)$ & & \\
\hline \multicolumn{6}{|l|}{ SEX OF NEONATE } \\
\hline Male & $105(52.5 \%)$ & $59(59 \%)$ & $46(46 \%)$ & 3.388 & NS \\
\hline Female & $95(47.5 \%)$ & $41(41 \%)$ & $54(54 \%)$ & & \\
\hline \multicolumn{6}{|l|}{ FETAL COMPLICATIONS } \\
\hline Jaundice & $05(2.5 \%)$ & $04(4 \%)$ & $01(1 \%)$ & 39.93 & $* * * *$ \\
\hline Extremely critical & $06(3 \%)$ & $00(0 \%)$ & $06(6 \%)$ & & \\
\hline Respiratory problems & $19(9.5 \%)$ & $00(0 \%)$ & $19(19 \%)$ & & \\
\hline NICU (Other complications) & $21(10.5 \%)$ & $00(0 \%)$ & $21(21 \%)$ & & \\
\hline \multicolumn{6}{|l|}{ GESTATION AGE } \\
\hline $\begin{array}{l}\text { Extremely preterm (less than } 28 \\
\text { weeks) }\end{array}$ & $08(8 \%)$ & - & $08(8 \%)$ & & \\
\hline Very preterm (28-32 weeks) & $16(16 \%)$ & - & $16(16 \%)$ & & \\
\hline $\begin{array}{l}\text { Moderate to late preterm }(32-37 \\
\text { weeks) }\end{array}$ & $76(76 \%)$ & - & $76(76 \%)$ & & \\
\hline $37-38$ weeks & $11(11 \%)$ & $11(11 \%)$ & - & & \\
\hline 38-39 weeks & $48(48 \%)$ & $48(48 \%)$ & - & & \\
\hline 40 weeks and above & $41(41 \%)$ & $41(41 \%)$ & - & & \\
\hline
\end{tabular}

Table 2. Comparing variables within PTB sub-categories.

\begin{tabular}{|c|c|c|c|c|c|}
\hline Variables & & Gestational Age & & Chi- Square value & $\begin{array}{l}\text { p- } \\
\text { value }\end{array}$ \\
\hline MATERNAL AGE & $\begin{array}{l}\text { Extreme PTB }(<28 \\
\text { weeks })\end{array}$ & $\begin{array}{l}\text { Very PTB (28-32 } \\
\text { weeks) }\end{array}$ & $\begin{array}{l}\text { Moderate PTB (32-37 } \\
\text { weeks) }\end{array}$ & & \\
\hline Below 20 & $01(12.5 \%)$ & $06(37.5 \%)$ & $25(32.89 \%)$ & 63.46 & $* * * *$ \\
\hline $20-25$ & $02(25 \%)$ & $05(31.25 \%)$ & $16(21.05 \%)$ & & \\
\hline $26-30$ & $01(12.5 \%)$ & $03(18.75 \%)$ & $25(32.89 \%)$ & & \\
\hline $31-35$ & $03(37.5 \%)$ & $01(6.25 \%)$ & $08(10.53 \%)$ & & \\
\hline Above 35 & $01(12.5 \%)$ & $01(6.25 \%)$ & $02(2.63 \%)$ & & \\
\hline \multicolumn{6}{|l|}{ BMI RANGES } \\
\hline Severe Underweight & $00(0 \%)$ & $01(6.25 \%)$ & $06(7.89 \%)$ & 15.15 & NS \\
\hline Underweight & $01(12.5 \%)$ & $02(12.5 \%)$ & $13(17.11 \%)$ & & \\
\hline Normal & $04(50 \%)$ & $07(43.75 \%)$ & $31(40.79 \%)$ & & \\
\hline Overweight & $02(25 \%)$ & $04(25 \%)$ & $23(30.26 \%)$ & & \\
\hline Obese & $01(12.5 \%)$ & $02(12.5 \%)$ & $03(3.95 \%)$ & & \\
\hline \multicolumn{6}{|l|}{ Hb levels } \\
\hline 7 to 9 & $04(50 \%)$ & $05(31.25 \%)$ & $14(18.42 \%)$ & 48.74 & $* * * * *$ \\
\hline 9 to 11 & $03(37.5 \%)$ & $08(50 \%)$ & $25(32.89 \%)$ & & \\
\hline 11 to 13 & $01(12.5 \%)$ & $02(12.5 \%)$ & $30(39.47 \%)$ & & \\
\hline Above 13 & $00(0 \%)$ & $01(6.25 \%)$ & $07(9.21 \%)$ & & \\
\hline \multicolumn{6}{|c|}{ Previous obstetric complication } \\
\hline SA/ miscarriage & $05(62.5 \%)$ & $06(37.5 \%)$ & $04(5.3 \%)$ & 22.59 & $* * * *$ \\
\hline Previous PTB/ Still Birth & $03(37.5 \%)$ & $07(43.75 \%)$ & $21(27.63 \%)$ & & \\
\hline \multicolumn{6}{|l|}{ HIGH BP } \\
\hline Total Cases & $08(8 \%)$ & $16(16 \%)$ & $76(76 \%)$ & 1.164 & NS \\
\hline Affected Cases & $02(25 \%)$ & $08(50 \%)$ & $44(57.89 \%)$ & & \\
\hline
\end{tabular}

Neonatal factors: Neonate's birth weight was divided into three categories: below 1 $\mathrm{kg}$, between 1-2 kg and more than $2 \mathrm{~kg}$, and was highly significant for PTBs below $1 \mathrm{Kg}$ $(\mathrm{p}<0.0001)$. The sex of newborns was nonsignificant between the two groups. Significantly higher number of PTB neonates suffered from complications such 
as being extremely critical, respiratory problems and other complications and were admitted to NICU due to less development $(p<0.0001)$.

We divided the gestational age into six categories: three categories for normal as 37-38 weeks, 38-39 weeks and 40 weeks and above, similarly three types of PTB as extreme (below 28 weeks), very (28-32 weeks) and moderate/ late (32-37 weeks) PTB. It is found that most of the normal births took place between 38-39 weeks, followed by 40 weeks and lastly, 37-38 weeks. Whereas, in the case of PTB, out of the total 100 births, maximum births (76) were observed in moderate to late preterm (32-37 weeks), followed by 16 in very (2832 weeks) and 8 in the extreme (below 28 weeks) PTB.

\section{DISCUSSION}

In this study, we observed many factors that affect the outcome of the pregnancy. Awareness about the factors that induce changes in the intrauterine condition, specifically physiological and pathological, affecting maternal and foetal health, foetus growth in the uterus during prenatal life and further postnatal growth and development are essential.

In our study, we observed a significant number of PTB cases in the teenage group. The probable reason behind it could be the competition for nutrients between the mother and foetus, ${ }^{[13]}$ as during the teenage years female herself is in a growing phase. Thus, it is scientifically believed that conceiving a baby after at least 20 years of maternal age is advisable for both mother and infant's health. In support of our results, we noted that several studies have also confirmed increased chances of preterm birth risk in teen pregnancy even after controlling other risk factors. [11,14] When we compared PTB sub-categories, teen pregnancy showed the risk for very and moderate PTBs while maternal age above 30 years showed the risk for the extreme PTBs, which means both teen and above 30 years of maternal age elevated risk of PTB in our study population. Furthermore, we observed maximum normal births in the age group of 20 to 25 years, which appears to be the safest and most fertile period for conceiving. A progressive rise in the incidence of PTBs detected after 25 years of age is possibly due to ageing, which affects females' physiological status, and fertility complications are very common nowadays in the late 30 s and may also complicate pregnancy further. In our society, females plan pregnancy mostly in their late 20 s to early 30s; therefore, we noted lesser deliveries after 30 years of maternal age. Yet, a significant number of PTBs were observed after 30 years of maternal age rather than full-term births. A large retrospective cohort study on the Canadian population by Fuchs et al. observed an elevated PTB risk after 35 years of age. ${ }^{[10]}$ Moreover, in the incidence of the adverse perinatal outcome, including preterm birth, a well-known correlation between maternal age and parity, specifically young multiparity and older primiparity, has greater risks. [15] Additionally, older primiparas might have a greater chance of preterm birth than older multiparity. [16] Though, we have not observed a significant correlation between primiparity and multiparity with PTB outcome. In multiparity, the interpregnancy interval should not be less than six months as a certain amount of time would be required to replenish the nutritional stores, recover internal organs, eliminate chances of infection and recover from post-pregnancy stress. ${ }^{[17]}$ Fortunately, not a single case in our study group had an interval of less than six months between pregnancies. Therefore, large population-based studies may show the correlation of less intermediate pregnancy intervals with PTB.

One of the probable reasons behind the high numbers of full-term births in the urban area is readily available resources and medical facilities which facilitate mothers to reach out for help in discomfort situations, contrast to that, major problems of urbanisation such as environmental 
pollution, inflation and stressful life make living difficult even more as most of these women belonged to low socioeconomic background, which could be the reason for high numbers of PTBs. A large populationbased study by DeFranco et al. suggested that environment independently affect birth outcomes, despite accounting for many sociodemographic, obstetric, medical, and other variables; they further noted that women living in socioeconomically deprived areas have a higher risk of preterm birth. [18] Also, we noticed higher PTB frequency in rural and slum areas, apparently because of lacking sufficient resources, right information, medical facilities, ignorance of the ill conditions, strenuous activities, and competition for earning daily wages. From the literature, it is known that maternal tobacco consumption in the form of mishri (pyrolysed and powdered tobacco), betel quid (paan) with tobacco, gutka, and paan masala can shorten the gestation period and increase the number of preterm birth and low birth weight (LBW) babies. [19] Moreover, Rogers observed that secondhand smoke exposure also affects birth weight and increases the risks of small for gestational age (SGA) and LBW births. ${ }^{[20]}$ However, in our study, we found only 14 cases of tobacco addiction out of 100 PTB cases, and statistical analysis revealed no significant difference between the cases and controls. Thus, no correlation between tobacco uses and birth outcomes was observed by us.

In the case of family structure, i.e., nuclear and joint family, two possibilities are there, leading to equal probabilities for PTB as there is no significant difference seen in both the groups. In the joint family, due to more responsibilities and social pressures on women, there may be more preterm birth chances. Contrarily, the positive side of living in a joint household is that persons are available to take extra care of the mother and share responsibilities, thereby raising the possibility of full-term deliveries. Nowadays, couples might live separate from their parents due to having a job or working in different cities or states. The young mothers might not get enough care, and no elderly family member is directly available to guide pregnancy maintenance, which can cause PTB and other pregnancy-related complications, as observed in a nuclear family setting. On the other hand, the probability of delivering full-term birth could be fewer responsibilities, less stress and independence. Out of all these possibilities, we firmly believe that mother and fetal health individually depends on the type of their relationship with their spouse and inlaws. Besides that, Collins et al. observed that exposure to interpersonal racism might be a risk factor for pregnant women at an individual level and expressed the cumulative impact on the social level that affected childbirth outcomes. ${ }^{[21]}$ A report by Auger et al. suggested that the material deprivation is linked to causing PTB rather than social deprivation. ${ }^{[22]}$

More than $70 \%$ of all females were literate and showed a considerable impact on birth outcomes as significant number of control literate women with full term deliveries were observed. Literacy helps females understand the value of good hygiene practice and the right knowledge about reproductive physiology, especially in adolescent age and empowerment. Luo et al. observed a higher risk of PTB in the group of women who did not finish high school and lived in poorer areas. ${ }^{[23]}$ El-Sayed and Galea found that more educated women have ready access to obstetrical interventions, such as elective caesarean sections, than less educated women, which could explain why more educated women have a higher risk of PTB. ${ }^{[24]}$ However, Auger et al. found no risk or difference in highly educated and slightly lower educated groups. ${ }^{[25]}$

Based on our observations, it is evident that the mother's BMI and proper diet play a vital role in the birth outcome. Mothers with very low or high BMI were found to be at risk of delivering preterm 
since low BMI, i.e., severely underweight and underweight, may not fulfill growing foetus's nutritional demand sufficiently and can increase her risk for gestational anaemia, hypertension, miscarriages and preterm delivery or even maternal mortality. Maternal high BMI (overweight and obese) is also problematic for obesity-related pregnancy disorders such as endothelial dysfunction, insulin resistance, oxidative stress, lipotoxicity and PTB. A Swedish nationwide cohort study of more than 1.5 million deliveries found that overweight and obesity in pregnant women is associated with an increased risk of premature delivery, especially extreme premature birth. [8] However, in contrast to that, Hendler et al. found that the total PTB rate was lowered in obese women; the probable reason behind it could be the length of the cervix. ${ }^{[26]}$ In obese women, the prevalence of short cervix is significantly lower than normal or underweight women, which may reduce the risk of PTB. Moreover, Bhattacharya et al. observed better pregnancy outcomes in underweight females. ${ }^{[6]}$ A retrospective study on 11,726 women by Lynch et al. also observed a significant increase in preterm birth incidence at the extremes of BMI. ${ }^{[27]}$ While there is a major contradiction in determining whether a vegetarian or mixed diet is advantageous during the pregnancy and birth outcome in the literature, we have noticed a significant number of full-term births in the vegetarian group. Low intake of plant-based food has been shown to increase the risk of gestation-related issues, such as preeclampsia and pre-gravid obesity, increase genotoxicant susceptibility, and the onset of pediatric diseases. [28] An unbalanced diet leads to vitamin and mineral deficiencies such as vitamin B-12, iron, zinc, and iodine.

Haemoglobin levels outside the normal range create many health-related issues, especially during pregnancy, it plays a significant role in maintaining the good health of the mother and growing foetus. Increased PTB when Hb levels were below average $(>11 \mathrm{~g} / \mathrm{dL}$ - maternal anaemia), as observed by us, was probably due to the lack of oxygen supply to the foetus as low $\mathrm{Hb}$ levels reduces the oxygen-carrying capacity of the blood. Furthermore, from the literature, it is evident that other than PTB, maternal anaemia is also linked with low birth weight, small-for-gestational-age, stillbirth, perinatal and neonatal mortality, and adverse maternal outcomes (postpartum hemorrhage; preeclampsia). [12,29,30] Most of our study group females were from socioeconomically deprived backgrounds; thus, they might lack proper nutrients from food (iron, vitamins A and B12, folate, and riboflavin) that possibly leads to anaemia and low BMI. Chaparro and Suchdev emphasised the risk factors most prevalent causing anaemia in low- and middle-income countries include, nutritional deficiencies, infection/inflammation, genetic hemoglobin disorders, iron deficiency (ID) and the role of inflammation and infection. [31] While looking into PTB sub-categories, we noticed low $\mathrm{Hb}$ levels $(7-9 \mathrm{~g} / \mathrm{dL}$ ) elevated risk of extreme $\mathrm{PTB}$, highlighting that low $\mathrm{Hb}$ levels should never be neglected. Not surprisingly, maximum normal deliveries were observed in the $\mathrm{Hb}$ range of 11-13 $\mathrm{g} / \mathrm{dL}$ by us and reported by Gonzales et al. [29] However, we observed an elevated risk of PTB when $\mathrm{Hb}$ levels were $13 \mathrm{~g} / \mathrm{dL}$ and higher. The probable reason behind it could be the high viscosity of the mother's blood due to high $\mathrm{Hb}$ levels, which may hinder the uteroplacental circulation and lead to foetal growth retardation or preterm birth. Various studies also have reported high $\mathrm{Hb}$ levels (more than $13 \mathrm{~g} / \mathrm{dL}$ ) and its adverse effects on the pregnancy outcome such as PTB, LBW, SGA, stillbirth, gestational diabetes and preeclampsia. ${ }^{[29,32]}$ However, a metaanalysis by Sukrat et al. which included Asian, European, African and North American population-based studies, did not find any risk of PTB in Hb levels $14 \mathrm{~g} / \mathrm{dL}$ or higher. ${ }^{[33]}$ We observed significantly high PTB cases in mothers with blood group B while blood group $\mathrm{O}$ mothers showed a lesser PTB risk. The mechanism or reason 
behind it is not known, and it could be a mere coincidence.

A notable correlation may lie between the mother's past bad obstetric history and its recurrence. We observed a repeated pattern of preterm birth or other adverse obstetric outcomes in women with a previous medical history of $\mathrm{SA} /$ miscarriage, stillbirth, and PTB, although the values were not significant. The control females were lacking or had a negligible history of such recurrence risk within the PTB subcategories; women who had previous obstetric complications delivered significantly higher extreme PTBs $(<28$ weeks) and very PTB (28-32 weeks). Even after known sociodemographic risk factors were accounted for, women with a history of three or more miscarriages had an increased risk of adverse perinatal outcomes such as preterm birth, very preterm birth, and perinatal death in subsequent pregnancies, according to a study by Field and Murphy. ${ }^{[34]}$ It is known that cervical incompetence leads to PTB, resulting from past abortions/ miscarriages. [35] A study conducted in Ethiopia strongly believed that the previous history of child-related adverse pregnancy outcomes could be a significant predictor for preterm birth. ${ }^{[36]} \mathrm{We}$ also reported significant PTB numbers in the group of mothers with other kinds of health complications such as abdominal pain, fever, jaundice, vertigo, severe vomiting, unusual swelling, drying of amniotic fluid, typhoid, unusual bleeding and cervical incompetence during pregnancy. Thus, the mother's illness and physiological complications during pregnancy affect the delivery outcome negatively. We analysed dysmenorrhea stress before the pregnancy to figure out any link with mothers' physical and reproductive strength as almost half of the women from our study group went through menstrual cramps before the pregnancy; however, no correlation was found with PTB.

During pregnancy, high blood pressure is one of the most common causes of morbidity and mortality in mothers and newborns. About $5 \%$ to $7 \%$ of pregnancies worldwide are affected by pregnancyinduced hypertension. ${ }^{[37]} \mathrm{We}$ observed that more than $50 \%$ of mothers in our study who delivered PTB were having hypertension, confirming a strong correlation between hypertension and PTB/ adverse pregnancy outcomes. Hypertension during pregnancy reduces the blood supply to the placenta, which reduces the consumption of oxygen and food for the foetus, leading to premature delivery and low birth weight. High blood pressure during pregnancy can cause placental complications and slow foetal growth. Chronic hypertension is associated with increased incidences of placental abruption, acute renal failure, cardiac decompensation, and cerebral accidents in the mother and of growth retardation and unexplained mid-trimester foetal death. [37] Moreover, extremely obese women with chronic hypertension are at special risk for cardiac decompensation near term. [37] Studies have provided a better understanding of the possible mechanisms responsible for pregnancy-induced hypertension's pathogenesis. Bangal et al. have observed an increased risk of preterm birth by $18 \%$ in mild pregnancy-induced hypertension $(\mathrm{PIH})$ and $48 \%$ in severe $\mathrm{PIH}$, especially among young primigravida in the rural population of Indian mothers. ${ }^{[38]} \mathrm{A}$ recent study conducted in the USA based black women by Premkumar et al. identified that women with gestational hypertension or chronic hypertension had 3.4 to 11.6 times more risk of preterm births than nonhypertensive women. ${ }^{[39]}$

Taking adequate supplements and medications is essential for the mother's health. Our study shows that more than $90 \%$ of the mothers who delivered full-term babies were very regular in folic acid and other vitamin supplementation, demonstrating that pregnant women should take the required medications during pregnancy to overcome vitamins and other deficiencies. WHO also recommends 30-60 mg daily iron during pregnancy. ${ }^{[40]}$ Studies have shown that folic acid supplementation 
reduces preterm birth risk and has protective effects on small for gestational age births. Furness et al. found that women who received folic acid gave birth to heavier and more full-term babies than those who did not, and also maternal RBC folate concentration in early pregnancy is associated with SGA and PTB. ${ }^{[41]}$ A study from south India by Muthayya et al. found a strong association between maternal low serum B12 levels and intrauterine growth restriction in urban Indian women. ${ }^{[42]} \mathrm{We}$ also observed a good number of healthy births among mothers who had consulted and visited doctors regularly and followed the doctor's instructions for keeping a healthy pregnancy, while those who did not maintained regularity in doctor's visits or medication elevated chances of having a preterm birth.

We did not notice a significant difference in male and female sex ratios in our population. However, there were relatively more female neonates delivered as PTB. According to the literature, it is evident that males are at a greater risk of delivering as a PTB and have a higher mortality risk. ${ }^{[43,44]}$ In the case of birth weight, most PTBs fell under the less than 2 $\mathrm{kg}$ category due to early parturition and less development. Furthermore, most normal births (full-term) fell above $2 \mathrm{~kg}$ of birthweight due to being born after complete gestation. Khashan et al. found out that any kind of stressful life events exposure before conception or during pregnancy affects newborns and significantly increases the chances to deliver with lower birth weight. [45]

Because of being born prematurely, neonates face many survival complications at birth and are frequently admitted to newborn intensive care units (NICU) for critical care. Most preterm infants born before 32 weeks of gestation will remain in the NICU until they are close to term, allowing their organs to grow sufficiently to function properly without the need of intensive care. [46] Out of many complications, pulmonary problems affect preterm babies maximally. Premature birth disrupts normal lung development in the womb, leading to major changes in lung function and physiology. ${ }^{[47]}$ Further, they noticed that the respiratory system immaturity of newborns at 34 to 36 weeks' gestational age causes greater morbidity in children leading to pulmonary function abnormalities that can even last into adulthood. Moreover, being a developing country, India does not have excellent medical facilities everywhere, which make survival of the infants more difficult. For that, the option of kangaroo mother care (KMC) exists. A study by Lawn et al. revealed the potential effect of KMC in lowincome countries, where other options for preterm baby care are limited due to a lack of neonatal care units, which are generally located in the far referral hospitals and might be understaffed and ill-equipped. [48] Since the sample size was small, we suggest further extensive population analysis to confirm the observations and recommendations for pregnant women for the mother and child's welfare.

\section{CONCLUSION}

PTB is undoubtedly a multifactorial condition as many environmental, physiological and epigenetic factors can trigger the condition. In our analysis between preterm and full-term groups, variables like maternal age, BMI at extreme ranges, $\mathrm{Hb}$ level below $9 \mathrm{~g} / \mathrm{dL}$ or above 13 $\mathrm{g} / \mathrm{dL}$, hypertension, medication and doctor's consultation, balanced diet, area of living, literacy, health complication during pregnancy, and blood group significantly elevated risk for PTB and must be taken into imperative consideration. Besides, other variables such as tobacco addiction, family structure and income, occupation and work during pregnancy, menstrual pain before pregnancy, parity, interpregnancy interval did not elevate risk for the PTB. Furthermore, maternal age, $\mathrm{Hb}$ and previous obstetric outcome were significant within the PTB categories, while high BP and BMI of mother did not show specific relevance. 
By understanding risk factors underlying PTB complications, pregnant mothers can be monitored and alerted priorly to reduce the rate of PTB effectively.

\section{Acknowledgement: None}

\section{Conflict of Interest: None}

\section{Source of Funding: None}

\section{Ethical Approval: Approved}

\section{REFERENCES}

1. Blencowe $\mathrm{H}$, Cousens $\mathrm{S}$, Chou $\mathrm{D}$, et al. Born too soon: the global epidemiology of 15 million preterm births. Reprod Health. 2013;10(S1):1-14.

2. Liu L, Oza S, Hogan D, et al. Global, regional, and national causes of under-5 mortality in 2000-15: an updated systematic analysis with implications for the Sustainable Development Goals. Lancet. 2016;388(10063):3027-35.

3. UN IGME (UN Inter-Agency Group for Child Mortality Estimation) 2020, Levels and Trends in Child Mortality: Report 2020: Estimates Developed by the UN InterAgency Group for Child Mortality Estimation (IGME). New York: United Nations Children's Fund; World Health Organization; The World Bank; United Nations, Department of Economic and Social Affairs, Population Division; United Nations Economic Commission for Latin America and the Caribbean, Population Division. [Internet]. [accessed 2021 Aug 17]. https://data.unicef.org/resources/levelsand-trends-in-child-mortality/

4. India Newborn Action Plan, Ministry of Health and Family Welfare, Government of India. 2014. [Internet]. [accessed 2021 Aug 17]. http://www. newbornwhocc.org/INAP_Final.pdf.

5. Ananth CV, Ananth CV, Vintzileos AM. Epidemiology of preterm birth and its clinical subtypes. J Matern Fetal Neonatal Med. 2006;19(12):773-82.

6. Bhattacharya S, Campbell DM, Liston WA, et al. Effect of body mass index on pregnancy outcomes in nulliparous women delivering singleton babies. BMC public Health. 2007;7(1):1-8.
7. Gravett MG, Rubens CE, Nunes TM. Global report on preterm birth and stillbirth ( 2 of 7): discovery science. BMC pregnancy childbirth. 2010;10(S1):1-16.

8. Cnattingius S, Villamor E, Johansson S, et al. Maternal obesity and risk of preterm delivery. Jama. 2013;309(22):2362-70.

9. Girsen AI, Mayo JA, Carmichael SL, et al. Women's prepregnancy underweight as a risk factor for preterm birth: a retrospective study. BJOG: Int J Obstet Gy. 2016; 123(12):2001-07.

10. Fuchs F, Monet B, Ducruet T, et al. Effect of maternal age on the risk of preterm birth: A large cohort study. PloS one. 2018;13(1):p.e0191002.

11. Marvin-Dowle K, Kilner K, Burley VJ, et al. Impact of adolescent age on maternal and neonatal outcomes in the Born in Bradford cohort. BMJ open. 2018;8(3):p.e016258.

12. Rahmati S, Azami M, Badfar G, et al. The relationship between maternal anemia during pregnancy with preterm birth: a systematic review and meta-analysis. $\mathbf{J}$ Matern Fetal Neonatal Med. 2020;33(15): 2679-89.

13. King JC. The risk of maternal nutritional depletion and poor outcomes increases in early or closely spaced pregnancies. J Nutr. 2003;133(5):1732S-1736S.

14. Akinbami LJ, Schoendorf KC, Kiely JL. Risk of preterm birth in multiparous teenagers. Arch pediatr adolesc med. 2000; 154(11):1101-07.

15. Schempf AH, Branum AM, Lukacs SL, et al. Maternal age and parity-associated risks of preterm birth: differences by race/ethnicity. Paediatr Perinat Epidemiol. 2007;21(21):34-43.

16. Lisonkova S, Janssen PA, Sheps SB, et al. The effect of maternal age on adverse birth outcomes: does parity matter? J Obstet Gynaecol Can. 2010;32(6):541-548.

17. Hogue CJ, Menon R, Dunlop AL, et al. Racial disparities in preterm birth rates and short inter-pregnancy interval: an overview. Acta Obstet Gynecol Scand. 2011;90(12):1317-24.

18. DeFranco EA, Lian M, Muglia LJ, et al. Area-level poverty and preterm birth risk: a population-based multilevel analysis. BMC Public Health. 2008;8(1):1-9.

19. Gupta PC, Sreevidya S. Smokeless tobacco use, birth weight, and gestational age: population based, prospective cohort study 
of 1217 women in Mumbai, India. Bmj. 2004;328(7455):1538-43.

20. Rogers JM. Tobacco and pregnancy: overview of exposures and effects. Birth Defects Res C Embryo. 2008;84(1):1-15.

21. Collins Jr JW, David RJ, Handler A, et al. Very low birth weight in African American infants: the role of maternal exposure to interpersonal racial discrimination. Am $\mathrm{J}$ Public Health. 2004;94(12):2132-38.

22. Auger N, Park AL, Gamache $P$, et al. Weighing the contributions of material and social area deprivation to preterm birth. Soc Sci Med. 2012;75(6):1032-37.

23. Luo ZC, Wilkins R, Kramer MS. Effect of neighbourhood income and maternal education on birth outcomes: a populationbased study. Cmaj 2006;174(10):1415-20.

24. El-Sayed AM, Galea S. Temporal changes in socioeconomic influences on health: maternal education and preterm birth. Am J Public Health. 2012;102(9):1715-21.

25. Auger N, Abrahamowicz M, Park AL, et al. Extreme maternal education and preterm birth: time-to-event analysis of age and nativity-dependent risks. Ann Epidemiol. 2013;23(1):1-6.

26. Hendler I, Goldenberg RL, Mercer BM, et al. The Preterm Prediction Study: association between maternal body mass index and spontaneous and indicated preterm birth. Am J Obstet Gynecol. 2005;192(3):882-86.

27. Lynch AM, Hart JE, Agwu OC, et al. Association of extremes of pre-pregnancy BMI with the clinical presentations of preterm birth. Am J Obstet Gynecol. 2014;210(5):428.e1-e9.

28. Pistollato F, Sumalla CS, Elio I, et al. Plantbased and plant-rich diet patterns during gestation: beneficial effects and possible shortcomings. Adv Nutr. 2015;6(5):581-91.

29. Gonzales GF, Steenland K, Tapia V. Maternal hemoglobin level and fetal outcome at low and high altitudes. Am J Physiol Regul Integr Comp Physiol. 2009;297(5):R1477-R1485.

30. Kumari S, Garg N, Kumar A, et al. Maternal and severe anaemia in delivering women is associated with risk of preterm and low birth weight: A cross sectional study from Jharkhand, India. One Health. 2019;8:100098.

31. Chaparro CM, Suchdev PS. Anemia epidemiology, pathophysiology, and etiology in low-and middle-income countries. Ann N Y Acad Sci. 2019; 1450(1): 15-31.

32. Abeysena C, Jayawardana P, De A Seneviratne R. Maternal haemoglobin level at booking visit and its effect on adverse pregnancy outcome. Aust N Z J Obstet Gynaecol. 2010;50(5):423-27.

33. Sukrat B, Wilasrusmee C, Siribumrungwong B, et al. Hemoglobin concentration and pregnancy outcomes: a systematic review and metaanalysis. BioMed Res Int. 2013. Article ID: 769057.

34. Field K, Murphy DJ. Perinatal outcomes in a subsequent pregnancy among women who have experienced recurrent miscarriage: a retrospective cohort study. Hum Reprod. 2015;30(5):1239-45.

35. Brown JS, Adera T, Masho SW. Previous abortion and the risk of low birth weight and preterm births. J Epidemiol Community Health. 2008;62(1):16-22.

36. Tsegaye B, Kassa A. Prevalence of adverse birth outcome and associated factors among women who delivered in Hawassa town governmental health institutions, south Ethiopia, in 2017. Reprod Health. 2018;15(1):193-202.

37. Lindheimer MD, Taler SJ, Cunningham FG. Hypertension in pregnancy. $\mathrm{J}$ Am Soc Hypertens. 2008;2(6):484-94.

38. Bangal VB, Giri PA, Mahajan AS. Maternal and foetal outcome in pregnancy induced hypertension: A study from rural tertiary care teaching hospital in India. Int J Biomed Res. 2011;2(12):595-99.

39. Premkumar A, Baer RJ, Jelliffe-Pawlowski LL, et al. Hypertensive disorders of pregnancy and preterm birth rates among black women. $\quad$ Am J Perinatol. 2019; 36(02):148-54.

40. World Health Organization [WHO]. Guideline: daily iron and folic acid supplementation in pregnant women. 2012. [Internet]. [accessed 2021 Aug 17]. http://apps.who.int/iris/bitstream/10665/777 70/1/9789241501996_eng.pdf

41. Furness DL, Yasin N, Dekker GA, et al. Maternal red blood cell folate concentration at 10-12 weeks gestation and pregnancy outcome. J Matern Fetal Neonatal Med. 2012;25(8):1423-1427.

42. Muthayya S, Kurpad AV, Duggan CP, et al. Low maternal vitamin B 12 status is 
associated with intrauterine growth retardation in urban South Indians. Eur J Clin Nutr. 2006;60(6):791-801.

43. Challis J, Newnham J, Petraglia F, et al. Fetal sex and preterm birth. Placenta. 2013;34(2):95-99.

44. Peelen MJ, Kazemier BM, Ravelli AC, et al. Impact of fetal gender on the risk of preterm birth, a national cohort study. Acta Obstet Gynecol Scand. 2016;95(9):1034-41.

45. Khashan AS, McNamee R, Abel KM, et al. Reduced infant birthweight consequent upon maternal exposure to severe life events. Psychosom Med. 2008;70(6):68894.

46. Ward RM, Beachy JC. Neonatal complications following preterm birth. BJOG: Int J Obstet Gy. 2003;110:816.

47. Colin AA, McEvoy C, Castile RG. Respiratory morbidity and lung function in preterm infants of 32 to 36 weeks' gestational age. Pediatrics. 2010;126(1): 115-128.

48. Lawn JE, Mwansa-Kambafwile J, Horta BL, et al. 'Kangaroo mother care to prevent neonatal deaths due to preterm birth complications. Int J Epidemiol. 2010; 39(suppl_1):i144-i154.

How to cite this article: Rathod P, Desai A, Chandel D. Evaluation of risk factors for preterm birth outcome in Gujarat, India. Int J Health Sci Res. 2022; 12(1):161-174. DOI: https://doi.org/10.52403/ijhsr.20220123 